\title{
JUVENTUDE E ESPAÇOS/EQUIPAMENTOS URBANOS PARA O LAZER NA CIDADE DE FLORIANÓPOLIS ${ }^{1}$
}

Recebido em: 23/04/2011

Aceito em: 01/12/2011

Laurien Cristhine Ziem Nascimento ${ }^{2}$

Maurício Roberto da Silva ${ }^{3}$

Universidade Federal de Santa Catarina - UFSC

Florianópolis - SC - Brasil

RESUMO: Este estudo se desenvolveu sob o tema de pesquisa "espaços/equipamentos para o lazer da juventude" numa perspectiva crítica sobre as questões políticas, econômicas e culturais da sociedade capitalista. O caminho teórico-metodológico foi inspirado nos pressupostos do materialismo histórico-dialético. Com base nos procedimentos teórico-metodológicos da pesquisa participante, busquei analisar as ideias e contradições sobre a problemática em questão. Trata-se de uma investigação na cidade de Florianópolis a partir dos jovens de Monte Serrat (classe trabalhadora empobrecida) e Ingleses (classe média), que apontou a necessidade de mais espaços/equipamentos para o lazer da juventude, de âmbito público, pois são escassas as possibilidades existentes para os jovens de ambas as classes sociais.

PALAVRAS CHAVE: Equipamento. Atividades de Lazer. Adolescente.

\section{YOUTH AND SPACES/URBAN EQUIPMENT FOR LEISURE IN THE CITY OF FLORIANOPOLIS}

ABSTRACT: This study was developed under the research theme "spaces/equipment for the leisure of youth" in a critical perspective on political, economic and cultural aspects of capitalist society. The way theoretical-methodological was inspired the assumptions in the historical-dialectical materialism. Based on theoreticalmethodological procedures the participant, I sought analyze the ideas and contradictions on the problem in question. This-research in the city of Florianopolis from young of Mount Serrat (working class impoverished) and Ingleses (middle class), which pointed out the need for more spaces/equipment for leisure youth, public, because they are few opportunities for young people from both the social classes.

KEYWORDS: Equipment. Leisure Activities. Adolescent.

\footnotetext{
${ }^{1}$ Artigo elaborado a partir da dissertação de mestrado "Espaços e equipamentos urbanos para o lazer da juventude na cidade de Florianópolis-SC", apresentada ao PPGEF/UFSC em 2009.

${ }_{2}^{2}$ Mestre em Educação Física pela Universidade Federal de Santa Catarina.

${ }^{3}$ Orientador da Dissertação de Mestrado
} 


\section{Introdução: Reflexões sobre o problema, delimitação e relevância social da pesquisa}

Este estudo se desenvolve sob o tema de pesquisa "espaços/equipamentos para o lazer da juventude". Trata-se de reflexões teórico-empíricas sobre o processo de compreensão acerca das questões políticas, econômicas e culturais da sociedade capitalista que priva, de um lado, a população em geral do atendimento e da satisfação das necessidades sociais básicas em termos de políticas públicas, tais como: trabalho, saúde, habitação, educação, saneamento, lazer e outras. De outro lado e de modo mais específico, priva a juventude do usufruto e dos benefícios oriundos das políticas públicas relativas aos espaços e equipamentos destinados ao lazer dessa geração.

Neste sentido, ao tentar recortar e delimitar o problema dos espaços urbanos para o lazer da juventude urge aguçar as análises críticas, acerca da problemática da conjuntura da economia política mais ampla, com ênfase nas questões objetivas de produção da vida: a centralidade do mundo do trabalho para o conjunto da classe trabalhadora e, sobretudo, para a juventude. Nestes meandros, o que se percebe é uma exploração generalizada de crianças (trabalho infantil), de jovens, de adultos, de velhos e de velhas, principalmente, nos países empobrecidos pela lógica da acumulação do capital, também chamados emergentes. O posicionamento epistemológico e teóricometodológico, nesta perspectiva, se dá, considerando que o problema de investigação sobre os "espaços/equipamentos urbanos para o lazer na cidade de Florianópolis", prescinde de um olhar sob a "problemática-conjuntura" maior, tornando, assim, o "problema" de pesquisa mais "problemático", para além da pseudoconcreticidade, isto é, situando-o no âmbito da "dialética do concreto" (KOSIK, 1976). Isto sugere enveredar por uma radicalidade, que nos leva a romper com a esfera da "pseudoconcreticidade" dos fenômenos, realizando, para tanto, um movimento de 
ruptura da "aparência" e, consequentemente, buscando os elementos "essenciais" de análise da problemática social, mais ampla em seus contextos macro e microssociais, políticos e econômicos (SILVA, 2007).

Deste modo, a investigação partiu de uma questão qualificada e delimitada ou "pergunta-síntese" (GAMBOA, 2007), a saber: existem espaços/equipamentos para o lazer na cidade de Florianópolis, inerentes a uma política pública consistente em termos de espaços/equipamentos para os jovens de diferentes classes sociais, visando o usufruto do chamado tempo de lazer/ "tempo livre"? A hipótese que subjaz à pergunta formulada pode ser assim redigida: “os espaços e equipamentos destinados ao lazer das diversas classes sociais estão concentrados, primordialmente, nas áreas" nobres "da cidade de Florianópolis, destinadas, portanto, às classes média (pequena burguesia) e classe alta (burguesia), de acordo com a categorização clássica de Marx (1991). Neste meandro, o objetivo geral do estudo consistiu em" investigar sobre a existência e o teor das políticas públicas dos espaços/equipamentos intraclasses para o lazer da juventude de Florianópolis, junto aos jovens, dos bairros de Ingleses e Monte Serrat/Alto da Caieira “.

\section{Caminhos teórico-metodológicos}

Procurando abordar as fundamentações e reflexões sobre o espaço urbano, classe social, juventude e lazer/ "tempo livre", percorremos um caminho teóricometodológico, tomando como base alguns pressupostos, de forma introdutória, as categorias e leis do materialismo histórico-dialético (LEFEBVRE, 1991b; TRIVIÑOS, 1987). Nesta perspectiva, usamos como referência a noção de "concreto pensado", cujo pressuposto indica que o real é concreto porque é síntese de múltiplas determinações 
(MARX,1985). Sendo assim, o materialismo histórico-dialético ${ }^{4}$ ou "concepção dialética da História", parte do princípio de que os processos históricos devem ser buscados, levando-se em consideração a forma pela qual os homens produzem os meios materiais, isto é,

[...] de que a produção, e, junto com ela, o intercâmbio de seus produtos, constituem a base de toda ordem social: em que toda a sociedade que se apresenta na História, a distribuição dos produtos e com ela, a articulação social em classes ou estamentos, se orienta pelo que se produz e pela forma como se produz, assim como pelo modo de permuta do que foi o produto. Nessas condições, as causas últimas de todas as modificações sociais e as subversões políticas não devem ser buscadas na cabeça dos homens, em sua crescente compreensão de verdade e de justiça eterna, mas nas transformações dos modos de produção e de intercâmbio, não se deve buscá-las na "Filosofia" ou na "Economia" da época que se trata (ENGELS, 1964, p.264).

De acordo com Lefebvre (1991b, p.67-68), o materialismo moderno, “constata a existência-real, efetiva, eficaz - da consciência e do pensamento", sendo que a realidade não pode ser definida isoladamente e nem ser destacada "da história humana social, do organismo humano e da natureza". Cabe à ciência experimentar, aprofundar e criticar as sensações e representações humanas, sendo que o materialismo supõe que elas "correspondem ao real segundo uma lei, que nos cabe investigar".

O materialismo histórico pode ser compreendido como "a ciência filosófica do marxismo que estuda as leis sociológicas que caracterizam a vida em sociedade, de sua "evolução histórica" e da "prática social" dos homens, do desenvolvimento da humanidade, trata dos fenômenos sociais, a partir da história, problematizando a totalidade da sociedade ao abordar: a) a estrutura socioeconômica; b) as forças

\footnotetext{
${ }^{4} \mathrm{O}$ materialismo dialético representa o caminho teórico que aponta a "dinâmica do real" na efervescência de uma da sociedade. Pode ser compreendida como a estratégia de apreensão da "prática social empírica" dos indivíduos em sociedade (grupos, classes e seguimentos sociais); de realização de "crítica" das ideologias e tentativas de articulação entre sujeito e objeto - ambos históricos- ambos humanos. Em suma, a dialética, refere-se ao "método de abordagem da realidade"- reconhecendo-a como processo histórico em seu peculiar dinamismo, provisoriedade e transformação (TRIVIÑOS, 1987, p.51); levando em conta a expressão de suas "leis universais", a saber: a) lei da interação universal (da conexão, da mediação recíproca de que tudo existe), b) lei do movimento universal (que implica a integração entre movimento interno e externo, promovendo o universal), c) lei da unidade dos contraditórios, d) lei da transformação da quantidade em qualidade (lei dos saltos) (Ibidem).
} 
produtivas e c) as classes sociais (as lutas de classe: entre capital e trabalho). Em síntese, o materialismo histórico esclarece conceitos como "ser social" (relações materiais dos homens com a natureza (o trabalho) e entre si que existem em forma objetiva, isto é, independentemente da consciência social - ideias jurídicas, políticas, filosóficas, estéticas, religiosas etc. (TRIVIÑOS, 1987, p.51).

Inspirados nessas leis e categorias, lançamos mão dos procedimentos teóricometodológicos da pesquisa participante, cujo eixo ontológico, epistemológico e teóricometodológico, leva em consideração o concreto pensado e a participação dos sujeitos como cultura de pesquisa, ou seja, a participação articulada à pesquisa determina o compromisso que subordina o próprio projeto científico e político-pedagógico da pesquisa ao projeto político e demandas sociais de relevância pública, oriundos da classe trabalhadora empobrecida, reconhecendo a sua cultura e sua história de classe (BRANDÃO,1986). Tendo em vista tais pressupostos, buscamos analisar, fundamentalmente, ideias, contradições, o particular e o universal, as mediações recíprocas e outras, presentes nas representações sobre a problemática sobre o espaço e equipamentos para o lazer da juventude, a partir, em primeiro lugar, do legado de Marx na sua obra O Capital, vol. I (1985) e, fundamentalmente, de um dos mais importantes comentadores da obra marxiana e estudioso sobre o espaço urbano- Henri Lefebvre (2001).

Este estudo, durante a construção da dissertação de mestrado, constituiu-se em dois momentos, a "fase exploratória" (o pré-campo) e o "campo propriamente dito". O pré-campo consistiu em dois eventos que ocorreram na cidade de Florianópolis, nos anos de 2007 e 2008, o Fórum Social da Juventude. Estes eventos foram denominados, neste estudo, de Fórum-campo 01 e Fórum-campo 02. O intuito desta inserção foi de, no Fórum-campo 01, buscar a compreensão dos jovens participantes no evento sobre os 
eixos temáticos juventude, lazer e espaço de lazer. No Fórum-campo 02, busquei ampliar as possibilidades de categorias investigativas emergentes a partir da compreensão dos participantes no evento sobre os eixos temáticos juventude, lazer, tempo livre, trabalho e espaço de lazer.

A investigação dos espaços/equipamentos para o lazer na cidade de Florianópolis, o campo propriamente dito, ocorreu a partir dos jovens de Monte Serrat/Alto da Caieira e Ingleses. Duas realidades de classe e vida cotidiana diferenciadas, pois no bairro Ingleses, os jovens eram estudantes (oitava série do Ensino Fundamental) de uma escola particular (classe média), já os jovens das "Comunidades do Maciço", estadual, localizada na comunidade de Monte Serrat ${ }^{6}$ (classe trabalhadora empobrecida).

As discussões contemplam aspectos referentes ao espaço urbano no sentido de que se entende que, no modo de produção capitalista, o espaço urbano é um bem econômico, é mais uma mercadoria geradora de valor, portanto, uma condição que leva à valorização de áreas centrais para especulação imobiliária, isto é, a propriedade privada torna-se um bem maior pela necessidade do lucro a qualquer custo, do fetiche do espaço urbano em nome da mais-valia e do dinheiro, em detrimento de espaços e equipamentos públicos e gratuitos, nos quais os trabalhadores possam produzir a vida

\footnotetext{
${ }^{5}$ Um conjunto de morros formam o Maciço Central de Florianópolis ou Maciço do Morro da Cruz: Morro Mariquinha, Monte Serrat, Nova Descoberta, Morro do Tico-Tico, Morro do 25, Nova Trento; Morro Do Horácio; Morro da Penitenciária; Morro da Queimada e Jagatá, Morro do Céu, Vila Santa Vitória, Serrinha, Caeira, Angelo Laporta, Santa Clara, Laudelina da Cruz, Jose Boiteux, Morro do Mocotó. Seu processo de ocupação iniciou no final do século XIX, recebendo escravos liberto e, mais recente, a migração e pauperização das populações rurais (PIMENTA e PIMENTA, 2005).

${ }^{6}$ Monte Serrat: comunidade que começou a ser povoada no século XIX e nas primeiras décadas do século XX se ampliou o número de moradores. Um fluxo migratório se iniciou nos anos vinte, em virtude das dificuldades inerentes à vida rural de cidades vizinhas à Florianópolis (ex.: Antônio Carlos), bem como devido a reformas urbanas implementadas na década de 20, na cidade de Florianópolis (região central). É uma comunidade constituída, em sua maioria, por negros.Comunidade vizinha à Monte Serrat, a comunidade do Alto da Caieira é a área mais recente com relação à ocupação e também a mais empobrecida do Maciço Central (PIMENTA e PIMENTA, 2005; WACHHOLZ, 2007).
} 
desalienada e vivenciar um tempo efetivamente livre das determinações do capital (HARVEY, 2004; SILVA, 1994).

No que pese aos espaços/equipamentos urbanos para o lazer na cidade de Florianópolis, ao fazer as primeiras observações sobre o problema, percebemos uma escassez e segregação dos espaços/equipamentos para o usufruto do lazer, como por exemplo, na perspectiva "geracional" (velhos, adultos, jovens e crianças), de "classe" (shoppings centeres, condomínios fechados, clubes entre outros), gênero e outras categorias sociológicas, tais como raça/etnia e cultura. Além dessas observações, a produção do conhecimento existente acerca da problemática aponta para a escassez, falta de políticas públicas ou ineficiência destas e da privatização e precarização dos espaços públicos, bens e serviços - em detrimento da democratização dos espaços, equipamentos e bens públicos, no que diz respeito à educação, saúde, lazer e outros, na cidade (MARCELLINO, 1983; PIMENTA e PIMENTA, 2005; SILVA, 1994).

Trata-se de um processo de apropriação dos espaços de contato social propiciado pela especulação imobiliária, transferindo gradualmente as possibilidades de contato social para o âmbito da iniciativa privada, tornando as relações sociais cada vez mais subordinadas ao valor das mercadorias. Além disso, contribuindo com a concentração de parte da população nas áreas centrais (áreas valorizadas pelo mercado) e a classe trabalhadora empobrecida (economicamente carente) nas áreas periféricas, sem acesso, ou usufruto precário das políticas sociais e públicas (saneamento, cultura, lazer, trabalho, educação e outras) como, por exemplo, as comunidades do Maciço do Morro da Cruz, comunidade Chico Mendes e outras.

A realidade urbana de Florianópolis, no que diz respeito aos seus espaços e equipamentos urbanos, está fundada na especulação imobiliária, processo de expansão capitalista urbana centrada na lógica da propriedade privada. Este processo de expansão 
capitalista, que se converte em especulação imobiliária, mostra-nos como a vida cotidiana está fundada nas relações dialéticas entre campo e cidade (LEFEBVRE, 1973); mostra-nos como a vida cotidiana, pautada pela divisão social do trabalho e classes sociais, constitui-se no mundo das mercadorias. Esse processo de migração do campo para sociedade urbana acontece acompanhado de uma acelerada degradação, destruição e desaparecimento do campo, dos camponeses, enfim, da classe trabalhadora rural. Assim, com todo esse processo destrutivo do trabalho no campo, as famílias são obrigadas a migrar para o mundo urbano, em cujos espaços de trabalho, lazer e moradia, sobrevivem de maneira iníqua, as crianças, os jovens, os adultos e os idosos.

Como já mencionamos, esta investigação toma como pressuposto ontológico e epistemológico a "concepção materialista da história", na qual a categoria fundamental é o trabalho como uma categoria universal concreta. Significa dizer que o trabalho é exercido como relação com a natureza e os outros homens. Isto implica, portanto, a existência da consciência e a representação do real (MARX e ENGELS, 2007). Neste sentido, o modo pelo qual os homens produzem seus meios de vida, depende, sobretudo, da natureza dos meios de vida já encontrados e que tem de reproduzir. Sendo assim, depende, portanto, das condições materiais de reprodução (SILVA, 1986), depende da organização corporal dos indivíduos e, por meio dela, como eles se relacionam com o restante da natureza (MARX e ENGELS, 2007, p.87). Todo esse processo implica abstrair que

[...] não tem história nem desenvolvimento; mas os homens ao desenvolverem sua produção e seu intercâmbio materiais, transformam também, com esta sua realidade, seu pensar e os produtos de seu pensar. Portanto, não é a consciência que determina a vida, mas a vida que determina a consciência (MARX e ENGELS, 2007, p.94). 
Seguindo esta linha de pensamento, pode-se dizer que o trabalho produz o espaço a partir do espaço existente anteriormente; a partir do modo de produção e o resultado, como espaço produzido, repercute sobre o anterior. Isto significa admitir que um modo de produção implica, um espaço organizado. Enquanto perdura um modo de produção, esse espaço é reproduzido estruturalmente e, neste sentido, repercute sobre o processo de sua reprodução. Assim sendo, a passagem de um modo de produção a outro, toma como ponto de partida o espaço existente já estruturado, assim como as formas de propriedade (SILVA, 1986).

O espaço urbano da cidade de Florianópolis contém a dimensão ontológica da “cidade do capital” (LEFEBVRE, 1999), está sedimentado nos valores da propriedade privada dos meios de produção da vida, cujo cerne ontológico é o trabalho humano abstrato. Nesta perspectiva, sobressai a divisão social do trabalho, divisão territorial do trabalho e a divisão de classes sociais. Neste processo, prevalece a circulação de mercadorias que geram valor de troca. Nestes termos, desaparece o caráter útil espaço (valor de uso), ao mesmo tempo em que

[...] desaparece o caráter útil dos produtos do trabalho; desaparece o caráter útil dos trabalhos neles representados e desaparecem também, as diferentes formas concretas desses trabalhos, que deixam de diferenciar-se um do outro para reduzirse em sua totalidade a igual trabalho humano, a trabalho abstrato (MARX, 1985, p.47).

É no âmbito da divisão das classes sociais e, por conseguinte, da divisão social do trabalho, onde se materializa também a divisão espacial, o "desenvolvimento desigual". O desenvolvimento desigual do capitalismo relaciona-se a categorias de apreensão da realidade, tais como: alienação, dependência, sub-denvolvimento, centro, periferia etc. (SILVA, 1986). Os espaços desiguais são, deste modo, ordenados segundo um sistema de fluxos que drena as riquezas da periferia para o centro. Assim, a 
apropriação da natureza e dos espaços humanizados, assume, um caráter de exploração, conforme se pode perceber na relação campo e cidade. Por outro lado, há neste mesmo "espaço desigual", aquilo que Lefebvre chamou de "conflito entre valor de uso e valor de troca", que se caracteriza pela transformação dos valores de uso em valores mercantis, mas também pelas lutas de resistência pela terra e pelo espaço (GUIGOU, 1986, p.128-129).

Em meio a esta lógica do capital, situam-se as contraditórias e muldimensionais problemáticas sociais, tais como a infância, a juventude e a velhice. No que diz respeito às políticas públicas, a realidade urbana tem colocado as questões da juventude de um lado, em segundo plano e, de outro, concebendo e oferecendo programas, cujas "boas práticas" fundamentam-se na crença da "inclusão social" ou "inclusão excludente" (GENTILI e ALENCAR, 2003) e da cidadania neoliberal ou "cidadania atrofiada" (SANTOS, 1987), visando tirar os jovens do mundo das drogas, da marginalidade e da pobreza, através da cultura, esporte e lazer (SILVA, SILVEIRA, ÁVILA, 2007). Neste sentido, ao refletir sobre o espaço social, de forma mais genérica, pode-se inferir que o capitalismo neoliberal ${ }^{7}$, com base no valor-mercantil, inculca a ilusão de integração social, mesmo solapando os direitos e aprofundando o enorme abismo entre a classe trabalhadora e a burguesia. No fundo, o que está em jogo é a contradição "inclusão X exclusão", levando-se em conta, na realidade atual, o acelerado declínio e obsolescência do modelo capitalista e a vertiginosa destruição das forças produtivas; fato este que vem determinando a possibilidade de acesso aos bens historicamente acumulados (TAFFAREL, s/d). Portanto, é de fundamental importância, pensar os espaços e equipamentos urbanos para a juventude, levando-se em consideração as contradições

7 Neoliberalismo: nova faceta do liberalismo (capitalismo de livre mercado), o Estado se afasta de suas obrigações (age em prol do capitalismo): privatização das empresas estatais, das organizações e instituições governamentais (habitação, transportes, educação, saúde e previdência), pois tudo deve ser empresa privada oportunidade de criar capital por meio da privatização dos lucros (sem participação dos cidadãos) e coletivização das perdas (os cidadãos pagam), (CO MBLIN, 1999; GENTILI, 2003). 
entre capital e trabalho, trabalho e educação e, trabalho e lazer; uma vez que essas relações se expressam na produção social e na apropriação privada dos bens culturais, transformando a educação, o espaço e a terra em mercadoria (TAFFAREL, s/d; GUIGOU, 1986, p.127). No entanto, essa vontade de transformar o espaço e a terra em mercadoria se choca com resistências sociais, pois hoje em dia desenvolve-se no espaço o conflito entre o valor de uso e o valor de troca. Neste sentido, vigora com bastante força a luta de classes, as resistências e as reivindicações dos trabalhadores, tendo como foco as lutas pela apropriação da terra e das práticas sociais no espaço; tendo como eixo um programa de transição na perspectiva da alternativa de projeto histórico para além do capital (TAFFAREL, s/d).

Neste contexto, a juventude, sobretudo, quando se refere à classe trabalhadora,vem sendo compreendida como um elemento potencializador de diversos "problemas sociais", tais como: falta de participação social, drogas, delinquência, problemas com a escola, entre outros. Sendo assim, busca-se enquadrar a juventude nos moldes desta sociedade capitalista (ABRAMO, 1997; PAIS, 1993), ao invés de levar em consideração que a classe trabalhadora empobrecida está inserida numa competitividade cotidiana, como a concorrência pelo emprego não qualificado e a habitação social (BONELLI, 2008); vivendo as agruras destrutivas do capital, como por exemplo: destruição dos direitos trabalhistas, que se convertem em exploração da força humana de trabalho, desemprego, subemprego (precarização do trabalho), e outras.

Em meio a tudo isso, destaca-se o lazer dos trabalhadores em geral, mas, em especial, o lazer da juventude. Este vem sendo compreendido pelo senso-comum como um momento de "ludicidade" e "diversão" ou "como espaço para a realização de valores conturbadores da tranquilidade, ordem e segurança social" (UVINHA, 2001, p.17). Um momento de compensação do trabalho escolar e do trabalho produtivo dos 
jovens ingressos no "mercado de trabalho"; assim como da transgressão que foge do tempo de positividade relacionada à formação humana, esperada pela sociedade dominante (adultez) de uma determinada época histórica ou pelos valores de determinadas comunidades de referência (BRENNER, DAYRELL e CARRANO, 2005). Contudo, este suposto "lazer transgressor", , pode se referir, qualitativamente, ao momento de superação e resistência, ligado ao potencial de criação, utopia, nos quais os consumidores críticos rebelam-se "contra os hábitos convencionais, estabelecendo, portanto, uma relação entre a busca de identidade e a fuga dos ditames do poder instituído” (SILVA, 2000, p.167), ou melhor, poderão, politicamente, rebelar-se contra as determinações impostas pelo capital à juventude da classe trabalhadora,

Todo esse processo, ao que tudo indica,visa à inclusão "excludente" (GENTILI e ALENCAR, 2003) dos jovens, ou melhor, visando moldar os comportamentos dos jovens às normas vigentes, na sociedade capitalista, surgem diversos meios, estratégias e programas como, formação profissional, ONGs, oficinas ocupacionais, entre outras (ABRAMO, 1997; PAIS, 1993). Nesta mesma direção se encontram ações relacionadas às políticas públicas para a Educação Física, Esporte e Lazer, contribuindo com os padrões sociais estabelecidos pela ordem social (OLIVEIRA e SILVA, 2007). Buscam-se maneiras de manter os jovens ocupados por meio do controle dos tempos, pois é através dos empregos do tempo (obrigatório, livre e imposto), que a vida cotidiana é organizada e controlada (LEFEBVRE, 1991). Neste sentido, considerando a relação dialética entre tempo e espaço, o tempo de lazer ou "livre", apesar das resistências e transgressões dos jovens e movimentos sociais, segue seu curso também controlado e manipulado pelas instituições educacionais, pelas políticas públicas "para aprofundar as diferenças de classe"; seguindo, assim, as

8 "Lazer quadrado" e "lazer transgressor" são expressões formuladas por Parker (SILVA, 2000), aonde o primeiro se refere às formas de lazer alienado, dos sujeitos adaptados às mazelas do sistema, que fornece divertimentos superficiais, prazer sem perturbações e que "condena" o lazer transgressor. 
mesmas determinações implícitas no espaço urbano: "a alienação do espaço do homem" (SANTOS 2009). Trata-se do "espaço que une e separa", isto é, "de um lado, há os consumidores de espaço, os famintos de infraestruturas; de outro lado, o resto. Os primeiros, firmas multinacionais e aparentadas, participam direta ou indiretamente da acumulação das economias avançadas, reservando para si as maiores vantagens" (SANTOS, 2009, p.31-32).

O espaço urbano, uma vez que se tornou "mercadoria universal", sofrendo os efeitos deste processo de estranhamento, uma vez que "a cidade torna-se estranha à região, a própria região fica alienada, já que não produz mais para servir às necessidades reais daqueles que a habitam" (SANTOS, 2009, p.28-350, grifos nossos), ou os jovens com seus lazeres, em suma, com suas demandas políticas, culturais e sociais.

Pode-se abstrair que, de um lado, há uma mercadorização dos tempos e espaços destinados ao lazer da juventude, não sendo possível um tempo realmente "livre" neste modo de produção capitalista, pois o "tempo livre" também é alienado pelo capitalismo, encontra-se envolvido na mesma alienação do tempo de trabalho (ANTUNES, 1995; SILVA, 2000). Este tempo, não se configura exatamente como um tempo de liberdade, de uma "vida com sentido", pois é manipulado com fins mercantis, podendo ser consumido como qualquer outra mercadoria. Nesta perspectiva, o tempo é mercantilizado, determinando o valor da força de trabalho, assim como são determinados os valores das mercadorias (tempo necessário para sua produção e reprodução). Além disso, nenhum tempo está livre das determinações dominantes, das normas estabelecidas pela classe dominante, pela mídia e outras instâncias do poder capitalista, tanto nacional (políticas públicas e governamentais), quanto internacionais (FMI, Banco Mundial). Por outro lado, quando se leva em conta às lutas sociais no 
âmbito da relação capital e trabalho, trabalho e educação, que se materializam nas lutas dos trabalhadores em nivel nacional e internacional por uma sociedade "para além do capital”, pode-se perceber outras formas de pensar os tempos e espaços destinados ao trabalho, ao lazer e à cultura da juventude da classe trabalhadora empobrecida.

\section{Juventude e equipamentos urbanos para o lazer na cidade de Florianópolis}

A centralidade deste estudo traz em seu bojo o problema do "usufruto dos espaços e equipamentos para o lazer na cidade de Florianópolis, oportunizados pelas políticas públicas para os jovens de diferentes classes sociais” (intraclasses), nomeadamente, do bairro de Ingleses (classe média) e do bairro Monte Serrat (classe trabalhadora empobrecida). Neste sentido, foi fundamental refletir o conceito de classe presente nos pressupostos marxianos, sem perder de vista a possível atualização deste conceito no âmbito da juventude que está imersa nas práticas sociais engendradas pelo capitalismo, no contexto do chamado capitalismo neoliberal.

A estrutura de classes é característica das sociedades capitalistas, que acabou se tornando um produto da nova sociedade que surgia, que tomava o poder, derrotando o feudalismo - a burguesia. A existência de classe social, como dois campos inimigos (burguesia e proletariado) é própria do sistema capitalista (MARX e ENGELS, 2003), sendo o proletariado ${ }^{9}$ o resultado da revolução industrial, da revolução burguesa (ENGELS, 1985). Esta classe vive à medida que encontra trabalho, mas só encontra

\footnotetext{
${ }^{9}$ Apesar de utilizarmos estes conceitos clássicos de classe sociais em Marx e Engels, reconhecemos que há na atualidade um enorme debate crítico sobre atualização e pertinência desses termos na atualidade, principalmente, tendo como referência os mandatos de Luiz Inácio Lula da Silva. Neste sentido, há na produção acadêmica um debate sobre o "lulo-petismo", um clima de triunfalismo sobre a suposta "nova classe média" no fenômeno da redistribuição da renda e, consequentemente na diminuição da pobreza, calcadas na queda de desigualdade. Ver a esse respeito o jornal "Le Monde Diplomatique" (Nov.2010), em cujo texto aparecem as seguintes denominações: alta classe média, baixa classe média e a massa trabalhadora e os miseráveis.Ver a esse respeito os livros ("Brasil em debate e 2003/2010-O Brasil em Transformação", Fundação Perseu Abramo); e "Brasil, Entre Passado e Futuro"(Fundação Perseu Abramo).
} 
trabalho "na medida em que seu trabalho aumente o capital" (MARX e ENGELS, 2003, p.51).

Tal como Engels (1985) descreve sobre a situação da classe trabalhadora em sua obra "A situação da classe trabalhadora na Inglaterra", descrevendo as condições e precariedade dos bairros operários (moradia, alimentação, saúde, vestimentas, etc.), é possível perceber semelhanças na atualidade. Assim, não é só para a cidade de Florianópolis, mas também para as demais cidades brasileiras e do mundo, pois a classe trabalhadora empobrecida está destinada a residir conforme suas condições econômicas, e até mesmo sendo redistribuída pelos bairros da cidade pelas ações de governo municipais, conforme a valorização imobiliária de determinados espaços da cidade ${ }^{10}$, levando-os a locais distantes de infraestrutura, tirando-os das vistas dos burgueses, ou mesmo pequenos burgueses, abandonando-os ao acaso.

A existência de classes sociais acarreta em desigualdade social, não apenas entre burguesia e proletariado, mas também entre a classe trabalhadora, ao que corresponde à chamada classe média ou pequena burguesia, constituída pelas camadas intermediárias e transitórias - as camadas médias - que acabam obscurecendo as linhas divisórias entre as classes (MARX, 1991).

Desta forma, a desigualdade social acarreta diferentes situações de vida, diferentes visões da realidade de vida, conforme percebemos, refletindo sobre essa questão de classe social, bem como estão expressos nos depoimentos dos jovens, nos quais os jovens de Monte Serrat/Alto da Caieira sentem-se discriminados na tentativa de um emprego, no acesso e usufruto dos espaços da cidade, o que reflete a visão da classe média (jovens de Ingleses) que vê a classe trabalhadora empobrecida como um perigo

\footnotetext{
${ }^{10}$ Como se os pobres fossem um "lixo humano", como descreve Malaguti (apud BRITO e NADER, 2009) a exemplo da situação do Rio de Janeiro: "os pobres do Rio de Janeiro são vítimas de crescente truculência oficial e, vistos como 'lixo humano' que precisa ser removido da cidade, uma vez que a presença dessa parcela da população é prejudicial aos grandes negócios e à especulação imobiliária”.
} 
social, estando a juventude relacionada a determinados problemas sociais como criminalidade, consumo de drogas e vandalismo (IULIANELLI, 2003)

Neste sentido, surgem políticas públicas voltadas ao jovem, tidas como uma saída de qualificação para o trabalho, à falta de experiência para ingressar no mercado de trabalho, sendo que muitas se voltam ao controle dos jovens (ABRAMO, 1997; PAIS, 1993). Contudo, são políticas que não resolverão o problema real da falta de emprego, uma vez que a raiz do problema é a sociedade capitalista, sendo necessário, então, outro tipo de sociedade que não tenha como objetivo o lucro capital, lutar pelo socialismo $^{11}$, como Marx e Engels defendiam em sua época.

Os jovens, muitas vezes, são considerados privilegiados ao lazer, mas na realidade, nem sempre isso é verdadeiro, uma vez que muitos, principalmente os jovens da classe trabalhadora empobrecida, buscam ocupar seu tempo com trabalho para as necessidades de sobrevivência. Desta forma, o "tempo livre" pode se tornar um problema para esses jovens, tanto com a preocupação de não estar trabalhando, quanto com a discriminação, taxando-os de delinquentes, de marginais.

Em linhas gerais, a compreensão entre os próprios jovens deste estudo sobre o entendimento de juventude, reflete a necessidade não só de estar empregado, mas também por entender que a juventude é uma fase na qual podem desfrutar um pouco mais o lazer. Já a idade adulta é entendida como uma fase da vida de responsabilidades e de trabalho, sendo que os jovens desejariam uma vida adulta com maior possibilidade para o lazer, para um tempo de brincadeiras como as crianças.

\footnotetext{
${ }^{11}$ Tentar superar esse sistema gerador de irracionalidades e crises constituindo-se em uma forma superior de organização social, funcionando a economia como se fosse formada por uma única empresa de porte gigantesco. Superando a fase inicial revolucionária (fusão do partido revolucionário com a classe trabalhadora), a sociedade caminharia para a abolição das classes (Estado-comuna), O socialismo deve se dar em nível global, pois o capitalismo não existe apenas em uma nação, mas sim globalizado.
} 


\section{Espaço/Equipamento para o lazer}

Esta discussão perpassa pela reflexão referente ao lazer, "tempo livre" e ao usufruto do tempo/espaço para o lazer, procurando manter a linha de raciocínio dos estudos marxistas, uma vez que essas questões estão intimamente relacionadas ao modo de produção capitalista, sendo, no entanto, diferenciado conforme as classes sociais em relação à quantidade e qualidade, ao acesso e oportunidades de lazer e "tempo livre" (ANTUNES, 2002; PADILHA, 2006).

Com relação ao usufruto do tempo/espaço para o lazer, percebemos que esses jovens procuram desfrutar do tempo disponível para o lazer, do tempo que lhes resta após as obrigações cotidianas, sejam elas relacionadas ao trabalho ou às atividades escolares, com atividades que lhes proporcionam prazer, mas que também dependem do espaço que encontram na sua comunidade.

Para entrar na discussão referente aos espaços/equipamentos para o lazer, necessário se faz refletir sobre o entendimento de espaço público que, de um modo geral, segundo a visão urbanística, compreende os espaços abertos da cidade, de uso comum, acessíveis e apropriados livremente pelas pessoas (LAVALLE, 2005; SERPA, 2004). Contudo, a apropriação desses espaços tem ocorrido de forma seletiva, diferenciada, restringindo o acesso a grupos sociais específicos, determinados pelo nível de renda (PADILHA, 2006; MACEDO, 1986).

Sendo assim, os espaços segregados se constituem na cidade, visando eliminar das vistas dos burgueses e pequenos burgueses as consequências nefastas que atingem a classe trabalhadora empobrecida (ENGELS, 1985; HARVEY, 2004). O que há nesta cidade, então, não tende a ser voltado para a classe trabalhadora empobrecida, mas sim para a elite (burguesia), assim como este jovem morador da comunidade do Morro do Mocotó denuncia (grifos nossos): 
Florianópolis eu acho que é uma cidade é, feito pra elite! Não é feito pra comunidade que tem menos condições, é muito feito pra elite! Então onde existe lazer é onde a elite alcança. As praças públicas não são feitas pras pessoas pobres circularem, até porque existe uma opressão de conduta aonde tu tem que ter sua forma de agir naquele local e a gente não tem essa forma de agir igual a quem vive no centro. Falta muito essa questão de ter um espaço onde se identifique com o povo.

Outra questão que inviabiliza ou que ameaça os espaços públicos são os grandes empreendimentos (especulação imobiliária/condomínios fechados, construção de shoppings e outros negócios) que se instalam nas cidades (SERPA, 2004). Um caso que é bem característico na cidade de Florianópolis, com grandes projetos privados que repercutem e ainda repercutirão sobre a transformação da paisagem e da sociedade (PIMENTA, 2005) como, por exemplo, os empreendimentos do Costão do Santinho Resort \& SPA e o Costão Golf (NUNES, WESTARB e SILVA, 2004). E outros projetos divulgados, publicados no "Relatório de oportunidades de investimentos" para o Estado de Santa Catarina, resultado do Congresso do Conselho Mundial de Viagens e Turismo (WTCC), que ocorreu na cidade de Florianópolis no ano de $2009^{12}$.

Outro aspecto que merece atenção nesta discussão se refere à democratização dos espaços/equipamentos para o lazer. Este ponto merece um questionamento a respeito da democratização dos espaços/equipamentos na sociedade capitalista, que no caso da cidade de Florianópolis, transforma o Plano Diretor Participativo em um espetáculo, fica apenas no discurso de participação, na realidade o processo de escolha fica sob o controle dos representantes, contribuindo com a lógica de mercado (CECCA, 1997; PIMENTA, 2005; SILVA, 1994), e as leis parecem ser a magia desta cidade, conhecida como "Ilha da Magia": "lei se faz, lei se desfaz", segundo a vontade das elites (CECCA, 1997).

\footnotetext{
${ }^{12}$ Sobre a discussão de projetos e empreendimentos na cidade de Florianópolis que ameaçam o espaço público ver a dissertação.
} 
Neste sentido, não há democratização, pois não há uma política que respeite os desejos, necessidades, demandas concretas e expectativas da população. Os desejos dos jovens desta pesquisa expressam a necessidade de espaços/equipamentos adequados para suas práticas de lazer, que parecem estar relacionadas às atitudes programadas para lugares determinados como: playground para crianças, jovens nas quadras e velhos “jogam dominó” (MACEDO, 1986). São expectativas de espaços que sejam públicos, de acesso gratuito, não somente no que diz respeito a praças e parques, mas também ao teatro. Nestes desejos também se reflete a lógica segregacionista dos espaços, pois os jovens da classe média temem o contato e a depredação por parte da classe trabalhadora empobrecida.

Entretanto, para que se realize efetivamente uma política pública, para que se concretize realmente uma democratização, acreditamos que seria possível por meio de uma intervenção política das pessoas das comunidades. Uma intervenção investigativa, participativa e política que questione e estude a sociedade capitalista a fim de permitir a compreensão da situação real da sociedade, das classes sociais, da classe trabalhadora, consequentemente, pensar os espaços/equipamentos para o lazer no sentido de construir uma nova sociedade, uma sociedade que venha a romper com o capitalismo, visando à igualdade social e não o acúmulo de capital nas mãos dos gestores e reprodutores da lógica implacável do capital (GENTILI, 1995).

\section{Considerações Provisórias}

Para os jovens de ambas as camadas sociais (classe trabalhadora empobrecida e classe média), a existência de espaços/equipamentos nas comunidades é limitada. Os espaços/equipamentos, existentes na comunidade de Ingleses, considerados públicos por serem espaços de uso comum, entendido como acessíveis a todos, sem restrição de 
entrada ou circulação (LAVALLE, 2005; SERPA, 2004), são os novos loteamentos e a estrada de acesso à praia do Santinho, que na realidade são caracterizados como espaços de circulação (ruas), apropriados pela comunidade, por jovens que o utilizam para diversas manifestações lúdicas, como os skatistas que providenciam instalações para a prática. Os demais espaços/equipamentos como os bares, restaurantes e parque aquático são considerados espaços de uso coletivo, mas privados, em virtude do acesso restrito determinado pela capacidade de consumo (LAVALLE, 2005), um fato que incide, em parte, também na praia ${ }^{13}$, considerada um espaço público, mas que sofre intervenção dos estabelecimentos privados que se apropriam e se instalam ao longo da orla delimitando uma parcela da extensão da praia para os consumidores (hotéis, bares e restaurantes).

Muitos jovens acabam se confinando em suas casas, ou casas de amigos, para um momento de lazer, não apenas pelo medo ou preconceito de uma classe sobre outra (MARCELLINO et al., 2007), mas pela falta de espaços/equipamentos abertos no bairro. Eles reclamam da existência de muitos lugares fechados (condomínios, muitos prédios), espaços esses que limitam a apropriação, regulamentam e normatizam as práticas cotidianas, criando simulacros de lugares que produzem os comportamentos e os modos de apropriação (SOBARZO, 2007). Diante disso, estes jovens manifestam a necessidade de espaços/equipamentos, como praça e quadras.

No caso da comunidade de Monte Serrat, o espaço/equipamento que utilizam para aproveitar ao máximo o tempo que possuem para o lazer/ "tempo livre", com brincadeiras que gostam ou o que é possível realizar na comunidade ${ }^{14}$, é o ginásio da escola. Este se encontra em estado precário, pois como são escassos os espaços de lazer

\footnotetext{
${ }^{13}$ Uma possibilidade que os jovens encontram na comunidade para manifestação da cultura lúdica, tais como: surfar, jogar bola ou simplesmente para se divertir.

${ }^{14}$ Jogar (futebol/voleibol), soltar pipa, tocar cavaquinho ou pandeiro, praticar esportes (projeto na escola), ficar em casa jogando vídeo-game, assistindo TV, no computador, brincar com os amigos, ir à festas, ir ao shopping, ir à lan house.
} 
na comunidade, ela acaba se apropriando, utilizando o ginásio, mas como não se sente parte da mesma, entram nesta instalação, depredam-na, mas nela não permanecem e sim se evadem (MARCELLINO, 1983; SILVA, 1994). Outro espaço que acaba se constituindo em um tipo de espaço/equipamento para o lazer é o espaço da caixa d'água em Monte Serrat, um pequeno espaço gramado que a comunidade se apropria para ser utilizado para um "bate bola" (futebol).

Um espaço que seria especificamente destinado ao usufruto do lazer é o campinho (futebol) na comunidade do Alto da Caieira, sendo que não apresenta estrutura adequada para o uso frequente (EIPPER, PIMENTA e PIMENTA, 2006), além de que ele estava sendo apropriado, utilizado como um canteiro de obras do PAC $^{15}$, dificultando ainda mais a apropriação do campinho pela comunidade como espaço para o lazer, para o futebol desses jovens. Como na comunidade há uma grande carência de espaços/equipamentos destinados ao tempo de lazer/ "tempo livre" e a falta de investimentos por parte do poder público, estes jovens encontram alternativas nas vias de acesso à comunidade; no Mirante do Morro da Cruz; na Escola Técnica e na quadra de Tênis da Federação no bairro Agronômica e o Parque da Luz (pouco frequentado devido à distância e dificuldade de utilizá-lo no período noturno pela falta de iluminação).

Como a estrutura de classes é característica da sociedade capitalista, na qual se estabelecem antagonismos entre classes (MARX e ENGELS, 2003), as diferenças dos espaços/equipamentos urbanos para o lazer, do ponto de vista das classes sociais, se destacam pelo sentimento de discriminação de um lado e preconceito ou medo do outro lado. Há, no entanto, um receio pela utilização dos espaços/equipamentos públicos por parte dos jovens da classe média em virtude do medo, da taxação da classe trabalhadora

\footnotetext{
${ }^{15}$ Programa de Aceleração de Crescimento.
} 
empobrecida como marginais ou "classes perigosas"; e/ou aqueles que não sabem utilizar o ambiente, os vândalos dos espaços públicos, assim salientam a necessidade de haver espaços para quem não pode pagar, sendo que há quem deseje um espaço/equipamento destinado ao usufruto de jovens da mesma classe, devendo, desta forma, ser um espaço pago, mas acessível às suas condições econômicas.

Representa, portanto, um sentimento de segregação, de criminalização dos pobres, diferenciando os espaços na cidade conforme as classes sociais. Uma condição que vai de encontro ao que Engels (1985) descreve sobre como a cidade é construída, de modo que cada classe habita sua determinada região conforme seus direitos capitalistas, isto é, espaço a ser usufruído apenas pelos pobres e espaços apenas usufruídos pela classe média e/ou alta, garantindo, assim, o não convívio com a população pobre, o contato com a miséria, bem como o sentimento de segurança que se torna ameaçado pela circulação da classe pobre, as classes perigosas, (ENGELS, 1985; CHALHOUB, 1990).

Os jovens de Monte Serrat demonstram a necessidade da existência de espaços/equipamentos públicos na cidade, não destacando a necessidade de que sejam diferenciados conforme as condições econômicas, pois percebem que a maior parte dos espaços existentes na cidade o acesso limitado àqueles que possuem melhor poder aquisitivo. Eles se sentem discriminados ao usufruírem o espaço da cidade, pois são tachados de perigosos por outros membros da sociedade que se encontram em padrão de vida superior, os quais, sentindo-se ameaçados, chamam a polícia (Força Pública) que atende às necessidades da burguesia a fim de impossibilitar qualquer organização da população (ENGELS, 1974). Estes jovens sentem a necessidade de que os espaços/equipamentos sejam públicos, gratuitos, de livre acesso e que possam ser 
frequentados a toda hora, em virtude dos demais espaços/equipamentos existentes na cidade serem de acesso limitado, como o teatro.

Os tipos de espaços/equipamentos desejados pelas diferentes classes acabam se diferenciando em certa parte, pois enquanto os jovens de Monte Serrat apontam a necessidade de um espaço/equipamento dispondo de quadras, campo de futebol, pista de bicicleta, teatro gratuito, espaço para shows (de apropriação da comunidade), os jovens de Ingleses demonstram a necessidade de espaços/equipamentos, alguns deles, semelhantes, mas outros que se caracterizam como espaços privados (clube, pesquepague), ou não (eventos públicos, parques, feira de artes públicas), mas também percebem uma necessidade de monitoramento de atividades ${ }^{16}$.

No que diz respeito a espaço/equipamento para o lazer de âmbito público, são escassas as possibilidades existentes, na realidade, nada ou quase nada há de espaços/equipamentos públicos que possam ser usufruídos para o lazer, e ainda assim, quando existem, estes são precários, ameaçados ou insuficientes para as diversas manifestações lúdicas juvenil, sem contar as diversificadas manifestações lúdicas dos demais segmentos da classe trabalhadora de uma comunidade, como os adultos, as crianças, os mais velhos e inclusive outros jovens, independente da classe social a que pertencem, pois espaços/equipamentos para o lazer na cidade de Florianópolis, frutos de uma política consistente para os jovens de diferentes classes sociais, visando o usufruto do chamado tempo de lazer/ "tempo livre" são praticamente inexistentes.

Quando o poder público manifesta, ou prevê a possibilidade de aplicação de algum espaço/equipamento que possa ser utilizado para o lazer, outras intenções estão em jogo, assim como espaços destinados ao uso público, ou que poderiam ser destinados ao uso público, tornam-se presas fáceis do capitalismo, estando na mira

\footnotetext{
${ }^{16}$ Estas atividades monitoradas devem ser questionadas, pois a exemplo dos "pacotes de lazer" oferecidos em ruas de lazer, praças e parques, a participação dos sujeitos geralmente se manifesta de forma conformista, consumindo apenas a atividade em si (SILVA, 1994).
} 
afinada dos empreendedores, da especulação imobiliária, até mesmo espaços considerados de preservação ambiental sofrem alterações em leis para que entrem no jogo do mercado imobiliário a favor da indústria do turismo (CECCA, 1997; PIMENTA e PIMENTA, 2002), pois o poder público faz parte do comitê administrativo dos negócios da classe burguesa (MARX e ENGELS, 2007 e 2003).

Diante das reflexões, achados e resultados apontados na pesquisa, convém pensar em "espaços de utopia" (HARVEY, 2004). Esses espaços somam-se dialeticamente aos "tempos" de luta dos movimentos sociais e sindicatos, visando construir uma sociedade e, consequentemente, uma cidade "para além do capital" (MÉSZÁROS, 2005), isto é, para além da propriedade privada dos meios de produção, para além da divisão abissal da sociedade de classes, que implica, consequentemente, uma constante luta de classes. Implica luta por uma sociedade construída sobre a base do socialismo, uma necessidade e possibilidade de superação da sociedade capitalista, tal como Marx já demonstrara, a partir da compreensão da gênese e da dinâmica dessa sociedade (capitalista) que é repleta de contradições e que os sinais de barbárie, como a exclusão social e pobreza se multiplicam (BENJAMIN, 2003). Uma luta contra o capitalismo - organizar, mobilizar, conscientizar e lutar pela transformação das condições de vida e trabalho, pela igualdade das possibilidades reais a cada cidadão (saúde, educação, moradia e trabalho), que deve ser lançada em nível internacional, pois o capitalismo não existe apenas em uma nação, mas de forma globalizada (IANNI, 2004).

\section{REFERÊNCIAS}

ABRAMO, Helena Wendel. Considerações sobre a tematização social da juventude no Brasil. Revista Brasileira de Educação, n.5/6. 1997. p.25-36. 
ANTUNES, Ricardo. Os sentidos do trabalho: ensaio sobre a afirmação e a negação do trabalho. 6.ed., São Paulo: Boitempo, 2002.

Adeus ao trabalho.Campinas:Editora da Unicamp,1995.

BENJAMIN, César. A necessária retomada do tema da transição. In: BENJAMIN, César (Org.). Marx e o socialismo. São Paulo: Expressão Popular, 2003.

BONELLI, Laurent. Juventude fora de controle. Le Monde Diplomatique Brasil, São Paulo, v. 1, n. 9, abr.2008.

BRANDÃO, Carlos Rodrigues (Org.). Pesquisa Participante. São Paulo: Brasiliense, 1986.

BRENNER, Ana Karina; DAYRELL, Juarez; CARRANO, Paulo. Culturas do lazer e do tempo livre dos jovens brasileiros. In: ABRAMO, H. W; BRANMCO, P. P. M. (Org.). Retratos da juventude: análises de uma pesquisa nacional. Porto Alegre: Instituto Cidadania, 2005.

BRITO, Gabriel e NADER, Valéria. "Pobres no Rio vivem dias de horror". Correio da Cidadania. 2009. Disponível em: http://www.correiocidadania.com.br/content/view/3180/9/. Acesso em: 27 abr. 2009.

CECCA (Centro de Estudos Cultura e Cidadania). Uma cidade numa ilha: relatório sobre os problemas sócio-ambientais da Ilha de Santa Catarina. Florianópolis: Insular, 1997.

CHALHOUB, Sidney. Classes Perigosas. Revista Trabalhadores, n.6, p.2 - 22, 1990.

COMBLIN, JOSÉ. O neoliberalismo: ideologia dominante na virada do século. Petrópolis: Vozes, 1999.

EIPPER, Susan; PIMENTA, Luís Fugazzola; PIMENTA, Margareth de Castro Afeche. Processo de ocupação e serviços urbanos no Maciço Central de Florianópolis: Serrinha e Alto da Caieira. EXTENSIO - Revista Eletrônica de Extensão, n. 4, 2006. Disponível em: <http://www.extensio.ufsc.br/> . Acesso em: 03 ago.2009.

ENGELS, Friedrich. A situação da classe trabalhadora na Inglaterra. Tradução de Rosa Camargo Artigas; Reginaldo Forti. São Paulo: Global, 1985.

A origem da família, da propriedade privada e do Estado. Tradução de Leandro Konder. Rio de Janeiro: Civilização Brasileira, 1974.

Anti-During. México: Grijalbo, 1964.

GAMBOA, Silvio S. Pesquisa em Educação: Métodos e Epistemologias. Chapecó: Argos, 2007. 
GENTILI, P. Como reconhecer um governo neoliberal? Um breve guia para educadores. In: SILVA, Luiz Heron \& AZEVEDO, José C. (Org). Reestruturação curricular: teoria e prática no cotidiano da escola. Petrópolis: Vozes, 1995. p. 128-137.

Como reconhecer um governo neoliberal?:Um breve guia para educadores. In:

SILVA, L. H. e AZEVEDO, J. C. (Org.). Reestruturação curricular: teoria e prática no cotidiano da escola. Petrópolis: Vozes, 2003.

GENTILI, P; ALENCAR.,F. Educar na esperança em tempos de desencanto. Petrópolis: Vozes, 2003.

GUIGOU, Jean-Luis. A terra e o espaço: Enigmas para os economistas. In: REYNAUD, Alain (et. al.). O espaço interdisciplinar. São Paulo: Nobel, 1986.

HARVEY, David. Os espaços de utopia. In: Espaços de esperança. São Paulo: Loyola, 2004. cap. 8, p.181-238.

IANNI, Octavio. Capitalismo, violência e terrorismo. Rio de Janeiro: Civilização Brasileira, 2004.

IULIANELLI, Jorge Atilo Silva. Juventude: construindo processos - o protagonismo juvenil. In: FRAGA, P. C. P.; IULIANELLI, J. A. S. (Org.). Jovens em tempo real. Rio de Janeiro: DP\&A, 2003. p.55-75.

KOSIK, K. A dialética do concreto. Rio de Janeiro: Paz e Terra, 1976.

LAVALLE, Adrián Gurza. As dimensões constitutivas do espaço público - Uma abordagem pré-teórica para lidar com a teoria. Espaço \& Debates, v. 25, p.33 - 44, 2005.

LEFEBVRE, Henri. A vida cotidiana no mundo moderno. Tradução de Alcides João de Barros. São Paulo: Ática, 1991. 1991b.

Lógica formal/lógica dialética. 5. ed. Rio de Janeiro: Civilização brasileira,

A vida cotidiana no mundo moderno. Tradução de Alcides João de Barros. São Paulo: Ática, 1991.

A cidade e a divisão do trabalho. In:

A cidade do capital. Rio de Janeiro: DP\&A, 1999. cap. 2, p.29- 73.

O direito à cidade. Tradução de Rubens Eduardo Frias. São Paulo: Centauro, 2001.

Entre lo urbano e lo rural. Barcelona: Provença,1973. 
MACEDO, Silvio Soares. Os espaços livres de edificação e o desenho da paisagem urbana. In: SEMINÁRIO SOBRE DESENHO URBANO NO BRASIL, 2, 1986, São Paulo. Anais... São Paulo: CNPq; FINEP, 1986. p.103-110.

MARCELLINO, N. C. Lazer e Humanização. Campinas: Papirus, 1983.

MARCELLINO et. al. Espaços e equipamentos de lazer em região metropolitana: o caso da RMC - Região Metropolitana de Campinas. Curitiba: OPUS 2007.

MARX, Karl. O capital: crítica da economia política. 5. ed. Tradução de Reginaldo Sant'Anna. Rio de Janeiro: Bertrand Brasil, 1991. v.6.

O capital: crítica da economia política. 2. ed. Tradução de Regis Barbosa e Flávio R. Kothe. São Paulo: Nova Cultural, 1985.v.1.

MARX, Karl; ENGELS, Friedrich. A ideologia Alemã. São Paulo: Boitempo, 2007.

Manifesto do Partido Comunista. Tradução de Pietro Nassetti. São Paulo: Martin Claret, 2003.

MÉSZÁROS, Istvan. A educação para Além do capital. São Paulo: Boitempo, 2005.

NUNES, C.C.; WESTARB, E. de F. F. do A.; SILVA, M.F.da. A prática do golfe, riscos ambientais e retorno social no norte da Ilha de Santa Catarina. Motrivivência, Florianópolis, v.16, n.22, p. 115 - 133, jun. 2004.

OLIVEIRA, Patrícia D. L. de; SILVA, Ana Márcia. A Educação Física na contramão das políticas públicas esportivizadas para infância e juventude. In: SILVA, M. R. (Org.). Esporte, educação, estado e sociedade. Chapecó: Argos, 2007. p.211-229.

PADILHA, Valquíria. Shopping Center: a catedral das mercadorias. São Paulo: Boitempo, 2006.

PAIS, José Machado. Culturas juvenis. Lisboa: Universidade de Lisboa,1993. (Coleção Análise Social).

PIMENTA, Margareth de castro A. Florianópolis como espaço público. In: (Org.). Florianópolis do outro lado do espelho. Florianópolis: UFSC, 2005. p.35-60.

PIMENTA, Luís F.; PIMENTA, Margareth de Castro A. Habitação e qualidade de vida urbana no Maciço Central de Florianópolis. In: PIMENTA, M. C. A. (Org.). Florianópolis do outro lado do espelho. Florianópolis: UFSC, 2005. p.123-148.

PIMENTA, Margareth de Castro A.; PIMENTA, Luís F. Políticas Públicas e Segregação Sócio-Espacial: o caso do Maciço Central em Florianópolis. In: ENCONTRO DA ASSOCIAÇÃO BRASILEIRA DE ESTUDOS POPULACIONAIS, 13, 2002. Anais... Ouro Preto, nov. 2002.

SANTOS, Milton. Pensando o espaço do cidadão. São Paulo: Universidade de São Paulo, 2009. 
SANTOS, Milton. O espaço do homem. São Paulo: Nobel, 1987.

SERPA, Ângelo. Espaço público e acessibilidade: notas para uma abordagem geográfica. GEOUSP - Espaço e Tempo, São Paulo, n. 15, p. 21 - 37, 2004.

SILVA, Maurício Roberto da. Democratização dos espaços urbanos para o lazer na cidade de Florianópolis. Motrivivência, v.5, n. 5/7, dez. 1994.

O assalto à infância no mundo amargo da cana-de-açúcar: onde está o lazer/lúdico? O gato comeu? 2000. 369 f. Tese - (Doutorado) Faculdade de Educação, Universidade Estadual de Campinas, São Paulo, 2000.

Apresentação: por que este livro? In: (Org.). Esporte, educação, estado e sociedade. Chapecó: Argos, 2007. p.13 - 33.

SILVA, M. R.; SILVEIRA, J.; ÁVILA, A. B. Políticas públicas para o esporte: cidadania e inclusão social. In: Maurício R. da (Org.). Esporte, educação, estado e sociedade. Chapecó: Argos, 2007. p.105-176.

SILVA, Armando Corrêa. As categotias como fundamentos do conhecimento geográfico. In: REYNAUD, Alain et. al. O espaço interdisciplinar. São Paulo: Nobel, 1986.

SOBARZO, Oscar. A produção do espaço público em presidente prudente: reflexões na perspectiva dos loteamentos fechados. 2007. Disponível em: http://www.ufrgs.br/labes/publicacoes/artigos/oscar art.htm . Acesso em: 25 jun. 2009.

TAFFAREL, Celi N. Z. A Exclusão social e educacional na sociedade brasileira. FACED/UFBA. (Uso restrito no trabalho do Coletivo UFSC - Sem correções). s/d. Disponível em: http://www.faced.ufba.br/rascunho_digital/textos/745.htm. Acesso em: 02 fev. 2011.

TRIVIÑOS, Augusto N. S. Introdução à pesquisa em Ciências Sociais. São Paulo: Atlas, 1987.

UVINHA, Ricardo Ricci. Juventude, lazer e esportes radicais. São Paulo: Manole, 2001 .

WACHHOLZ, Bianca. "Um centro de possibilidades". 2007. Trabalho de Conclusão de Curso (Graduação) - Departamento de Arquitetura e Urbanismo, Universidade Federal de Santa Catarina, Florianópolis, 2007.

\section{Endereço dos Autores:}

Laurien Cristhine Ziem Nascimento

Rua Dona Alta Lucas, 507 Rio Vermelho

Florianópolis - SC - 88060-310

Endereço Eletrônico: 1aurienziem@yahoo.com.br 
Laurien Cristhine Z. Nascimento e Juventude e Espaços/Equipamentos Urbanos para o Lazer...

Maurício Roberto da Silva

Maurício Roberto da Silva

Caixa postal, 5035-ag. Campus Universitário/UFSC

Trindade, Florianópolis - SC - 88.040-970

Endereço Eletrônico: mauran@uol.com.br 